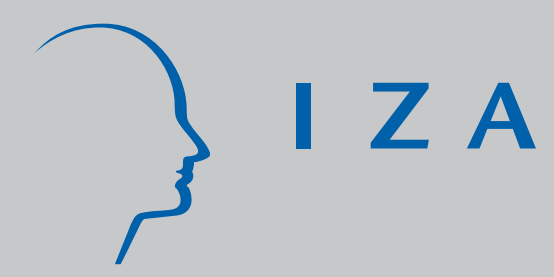

IZA DP No. 1340

Incentives in Tournaments with Endogenous Prize Selection

Christine Harbring

Bernd Irlenbusch

October 2004 


\title{
Incentives in Tournaments with Endogenous Prize Selection
}

\author{
Christine Harbring \\ University of Bonn \\ Bernd Irlenbusch \\ London School of Economics \\ and IZA Bonn
}

\section{Discussion Paper No. 1340 \\ October 2004}

\author{
IZA \\ P.O. Box 7240 \\ 53072 Bonn \\ Germany \\ Phone: +49-228-3894-0 \\ Fax: +49-228-3894-180 \\ Email: iza@iza.org
}

\begin{abstract}
Any opinions expressed here are those of the author(s) and not those of the institute. Research disseminated by IZA may include views on policy, but the institute itself takes no institutional policy positions.
\end{abstract}

The Institute for the Study of Labor (IZA) in Bonn is a local and virtual international research center and a place of communication between science, politics and business. IZA is an independent nonprofit company supported by Deutsche Post World Net. The center is associated with the University of Bonn and offers a stimulating research environment through its research networks, research support, and visitors and doctoral programs. IZA engages in (i) original and internationally competitive research in all fields of labor economics, (ii) development of policy concepts, and (iii) dissemination of research results and concepts to the interested public.

IZA Discussion Papers often represent preliminary work and are circulated to encourage discussion. Citation of such a paper should account for its provisional character. A revised version may be available directly from the author. 


\section{ABSTRACT \\ Incentives in Tournaments with Endogenous Prize Selection*}

Tournament incentive schemes offer payments dependent on relative performance and thereby are intended to motivate agents to exert productive effort. Unfortunately, however, an agent may also be tempted to destroy the production of his competitors in order to improve the own relative position. In the present study we investigate whether this sabotage problem is mitigated in a repeated interaction between the agents and the principal. As sabotage can hardly be observed in real-world organizations we employ a controlled experiment. Our data provide clear evidence that agents' behavior is not only guided by competition between agents but also by the possibility to punish the principal via sabotage.

JEL Classification: D23, J33, J41, L23, C72

Keywords: relative performance evaluation, personnel economics, sabotage, reciprocity, experiments

Corresponding author:

Bernd Irlenbusch

Interdisciplinary Institute of Management

London School of Economics

Houghton Street

London, WC2A 2AE

United Kingdom

Email: b.irlenbusch@Ise.ac.uk

\footnotetext{
* We thank two anonymous referees, Christian Grund, Matthias Kräkel, Reinhard Selten, and Dirk Sliwka for valuable comments. All errors are our own. We are grateful to Sebastian Kube who programmed the experimental software. Financial support by the Deutsche Forschungsgemeinschaft through grants IR 43/1-1, KR2077/2-1 KR2077/2-3 is gratefully acknowledged.
} 


\section{Introduction}

Currently there is a vivid discussion about the adoption of incentive systems that are based on relative performance evaluation. Personnel economists analyze the topic within the framework of tournament theory (see e.g. GIBBONS 1998, LAZEAR 1999, PRENDERGAST 1999). In a rank-order tournament pay is based on the relative performance of agents rather than on absolute performance. This offers a variety of advantages, e.g. the influence of global shocks is diminished, measuring ordinal performance is usually feasible at lower costs, and the induced competition among agents for obtaining the winner prize helps to reduce hidden action problems.

However, also severe drawbacks have been identified, which lead to controversial discussions, for example in the course of the increasingly frequent implementation of forced rankings in organizations. If employees are rated according to a forced ranking, they compete for a good evaluation as the absolute number of good ratings is fixed ex ante via a forced distribution of performance evaluations. The relative performance evaluation is often linked to a bonus pay system or the decision on promotion of high performers or advising low performers to leave the company. ${ }^{1}$ This management practice has been heavily criticized as cooperation of employees within an organization is feared to be put at risk. Employees may improve their relative position via increasing their productive activity but they can also try to deteriorate the performance of their competitors via destructive activities. In organizations such a sabotage activity can take any form of blocking cooperation such as actively withholding viable information, transferring false information or damaging work tools used by others. ${ }^{2}$

Of course, destructive activities in organizations are strictly forbidden as they might seriously harm the employer. Thus, it seems of eminent importance to analyze which factors could mitigate the exertion of sabotage activities. One obvious way to reduce the motivation to sabotage is to lower the tournament incentive by decreasing the difference between the payment obtained by the winners (winner prize) and the payment received by the losers (loser prize). This argument is introduced in the seminal paper by LAZEAR (1989), who explicitly

\footnotetext{
1 According to estimates a quarter of the Fortune 500 companies (e.g. General Electric, Cisco, Intel, Hewlett Packard etc.) link part of the individual benefits to a relative performance evaluation (see BOYLE 2001). Forced rankings are usually implemented to force evaluating managers to sufficiently differentiate their ratings, i.e. to use the whole bandwidth of grades (see e.g. MURPHY 1991). Recently, the statement of Infineon's former CEO Schumacher was heavily discussed in Germany as he announced that the 5\% low performers of Infineon were to leave the company. This is why forced rankings are also known as "rank and yank".

${ }^{2}$ For a famous example of sabotage in a sport tournament remember the Harding-Kerrigan scandal during the Olympic games of 1994: Kerrigan's rival Harding was injured in an attack hatched by Hardings's ex-husband to keep Kerrigan off the Olympic ice skating team.
} 
models a rank-order tournament with sabotage. Unfortunately, compressing wages also lowers the incentive to exert productive activities. Alternatively, a reinforcement of control activities may decrease sabotage activities but this may come with potentially high costs.

Insights from behavioral economics suggest an additional way to reduce the motivation for sabotage. Recently, several investigations have shown that reciprocal fairness plays an important role in employment relationships, see e.g. FEHR, GÄCHTER and KIRCHSTEIGER (1997), Charness (2000), Dufwenberg and Kirchsteiger (2000), FalK, Fehr, and FischBACHER (2000), ABBINK, IRLENBUSCH, and RENNER (2000). From this vast body of experimental evidence we know that reciprocity among individuals may evolve if parties can mutually influence their payoffs. If we assume that employees are motivated by a preference for reciprocal fairness, sabotage activities are likely to be reduced by a "friendly" action of the employer. An intention that is perceived as kind may be responded by a kind action in return. In our context for example, an employer's offer of high wages might be perceived as friendly and one might conjecture that employees respond to such a behavior with high productive effort but no or low sabotage activities.

The investigation of the interplay between fairness considerations towards the principal and the competition among agents induced by relative performance based incentive schemes is at its very heart an empirical question. Thus, in our study, we investigate the interaction of a principal and agents in an experimental tournament setting, where productive and destructive activities are feasible. We start to analyze agents' behavior in tournaments with exogenously given tournament prizes and afterwards we compare these results with a setting where a principal may repeatedly commit himself to different tournament prizes. Our experimental design allows us to analyze whether reciprocal fairness motives evolve if high or low wages can be selected on purpose. If this is the case we expect a reduction in sabotage as explained above. We focus on the variation of the winner prize while keeping all other parameters constant. As a consequence, an increase in the winner prize results in both, a higher prize differential between loser and winner prize and a higher total wage sum. ${ }^{3}$ If a principal selects a high winner prize the behavior of individually rational agents is driven by a stronger incentive for obtaining the winner prize. Simultaneously, a preference for reciprocal fairness may induce a friendly behavior towards the principal. While agents can achieve both purposes by increasing their productive activity, the exertion of the sabotage must be interpreted as a

\footnotetext{
3 For an example of such a procedure in an organization think of a situation, in which all employees receive a fixed minimum salary, i.e. the loser prize negotiated by a union. On top there might be a total amount of bonus payments, i.e. the amount of winner prizes, which can be varied by the employer and is distributed via a tournament rule (e.g. a forced ranking scheme). Or think of a fixed number of people who are going to be promoted and the employer commits himself to a certain salary attached to the new jobs.
} 
hostile action against the principal. Thus, incentives to increase the destructive activity with the winner prize follow from individual rationality, but incentives to lower sabotage would presumably result from reciprocal fairness.

As mentioned above in this study we opt for the method of a controlled experiment in the laboratory. This is due to several reasons. First of all, the experimental set-up allows us to analyze clear-cut institutional design features. Usually, when analyzing data from the field the design of the tournament scheme is exogenously given (e.g. KNOEBER and THURMAN 1994 , EHRENBERG and BOGNANNO 1990) and might not be appropriate for the research question under consideration. Moreover, in an experiment the performance of individuals can exactly be measured as the exertion of effort is abstractly modeled by the choice of a number. In studies using data from the field the individual's performance has to be approximated, for example by some company performance indicator or the score in sports tournaments (e.g. Main, O’Reilly and Wade 1993, Eriksson 1999, Becker and Huselid 1992). Most importantly, sabotage activities can hardly be observed in the field as it is forbidden in realworld organizations and therefore undertaken secretly. Thus, an experiment has the decisive advantage that one can observe sabotage activities without abstaining from behavior shown by "real" human actors. ${ }^{4}$ DRAGO and GARVEY (1998) approach a question related to our research focus. They investigate the influence of wage differentials in Australian work groups on the tendency to show "inverse" sabotage behavior, i.e. to help colleagues. They find that helping effort is indeed reduced if the wage dispersion is high. GARICANO and PALACIOSHuERTA (2000) analyze the effects of an exogenous increase of the prize differential in the Spanish soccer league. They take the number of defenders who aim to reduce the competitor's output, i.e. the number of goals, as a measure for sabotage activity. Additionally they count the number of yellow and red cards. According to their study productive activities and sabotage increase with the prize differential.

\footnotetext{
${ }^{4}$ Of course, we are aware that by choosing the experimental method we are forced to condensate the real-world setting to its very essentials - as it is always the case with economic modeling.
} 
study

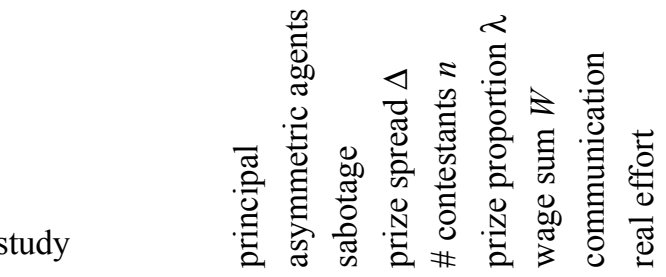

research focus / comments

\begin{tabular}{|c|c|c|c|c|c|c|c|c|c|c|}
\hline $\begin{array}{l}\text { BULL, SCHOTTER, } \\
\text { WEIGELT (1987) }\end{array}$ & & $x$ & & $\times$ & 2 & & $x$ & & & $\begin{array}{l}\text { comparison of tournaments and piece rates; advantaged } \\
\text { agents have lower effort costs; in equilibrium } \\
\text { advantaged agents exert higher effort than } \\
\text { disadvantaged ones }\end{array}$ \\
\hline $\begin{array}{l}\text { WEIGELT, } \\
\text { DUKERICH, } \\
\text { SCHOTTER (1989) }\end{array}$ & & $x$ & & $x$ & 2 & & $\times$ & & & $\begin{array}{l}\text { influence of discrimination in tournaments; advantaged } \\
\text { agents endowed with free extra output; no difference in } \\
\text { equilibrium effort between types }\end{array}$ \\
\hline $\begin{array}{l}\text { SCHOTTER, } \\
\text { WEIGELT (1992) }\end{array}$ & & $x$ & & & 2 & & & & & $\begin{array}{l}\text { effectiveness of affirmative action; advantaged agents } \\
\text { are endowed with free extra output or they have lower } \\
\text { effort costs }\end{array}$ \\
\hline $\begin{array}{l}\text { NALBANTIAN, } \\
\text { SCHOTTER (1997) }\end{array}$ & & & & & 2 & & & & & $\begin{array}{l}\text { comparison of different incentive schemes in groups; } \\
\text { groups compete against groups; effort contributions } \\
\text { modeled as public good within a group }\end{array}$ \\
\hline $\begin{array}{l}\text { HARBRING, } \\
\text { IRLENBUSCH (2001) }\end{array}$ & $\times$ & & & & 2 & & & & & $\begin{array}{l}\text { endogenous comparison of tournament and team } \\
\text { incentives; principal repeatedly chooses a tournament } \\
\text { or team incentive scheme }\end{array}$ \\
\hline $\begin{array}{l}\text { VAN DIJK, } \\
\text { SONNEMANS, VAN } \\
\text { WINDEN (2001) }\end{array}$ & & $x$ & & & 2 & & & & $x$ & $\begin{array}{l}\text { comparison of real effort in different incentive } \\
\text { schemes; real effort by graphically solving optimization } \\
\text { tasks }\end{array}$ \\
\hline $\begin{array}{l}\text { GNEEZY, NIEDERLE, } \\
\text { RUSTICHINI (2003) }\end{array}$ & & & & & 6 & & & & $x$ & $\begin{array}{l}\text { gender differences in piece rate schemes and in } \\
\text { tournaments; real effort by solving mazes; groups } \\
\text { consisted either of women or men or of both }\end{array}$ \\
\hline HARBRING (2003) & & & & & 2 & & & $x$ & & influence of communication in tournaments and teams \\
\hline $\begin{array}{l}\text { HARBRING, } \\
\text { IRLENBUSCH (2003a) }\end{array}$ & & & & & $x$ & $\times$ & $x$ & & & $\begin{array}{l}\text { influence of tournament design: tournament size and } \\
\text { prize structure; number of agents varied: } 2,3,6\end{array}$ \\
\hline $\begin{array}{l}\text { HARBRING, } \\
\text { IRLENBUSCH (2003b) }\end{array}$ & $x$ & & $x$ & & 4 & $\times$ & $x$ & & & $\begin{array}{l}\text { comparison of active and passive principals; wage sum } \\
\text { varied by altering the number of winner prizes }\end{array}$ \\
\hline $\begin{array}{l}\text { HARBRING, } \\
\text { IRLENBUSCH (2003c) }\end{array}$ & $x$ & & $\times$ & $\times$ & 4 & $x$ & $\times$ & & & $\begin{array}{l}\text { passive principals; wage sum varied by altering the } \\
\text { number of winner prizes or changing the wage spread }\end{array}$ \\
\hline $\begin{array}{l}\text { HARBRING, } \\
\text { IRLENBUSCH (2003d) }\end{array}$ & $x$ & & $\times$ & & $x$ & $x$ & $\times$ & & & $\begin{array}{l}\text { passive principals, number of agents varied: } 2,4,8 \text {; } \\
\text { wage sum varied by altering number of winner prizes }\end{array}$ \\
\hline $\begin{array}{l}\text { HARBRING, } \\
\text { IRLENBUSCH (2003e) }\end{array}$ & $\times$ & & $\times$ & $\times$ & 3 & & $\times$ & $\times$ & & $\begin{array}{l}\text { active principals; fixed wages possible; wage sum } \\
\text { varied ceteris paribus; communication between agents } \\
\text { and principals; }\end{array}$ \\
\hline $\begin{array}{l}\text { ORRISON, } \\
\text { SCHOTTER, WEIGELT } \\
(2004)\end{array}$ & & $x$ & & & $x$ & $x$ & $x$ & & & $\begin{array}{l}\text { group size in asymmetric tournaments; advantaged } \\
\text { agents endowed with free extra output; number of } \\
\text { agents varied: } 2,4,6 \text {; wage sum varied by altering the } \\
\text { number of winner prizes }\end{array}$ \\
\hline $\begin{array}{l}\text { HARBRING, } \\
\text { RUCHALA (2004) }\end{array}$ & & $\times$ & & $x$ & 2 & & $\times$ & & & $\begin{array}{l}\text { sorting in asymmetric tournaments by varying the wage } \\
\text { spread; advantaged agents have lower effort costs; } \\
\text { wage sum varied by changing the winner prize }\end{array}$ \\
\hline $\begin{array}{l}\text { FALK, FEHR } \\
\text { (in preparation) }\end{array}$ & $\times$ & & $x$ & $x$ & 2 & & & $x$ & & $\begin{array}{l}\text { active principals; fixed wages possible; communication } \\
\text { between agents }\end{array}$ \\
\hline
\end{tabular}


There are already several illuminating experimental studies on tournament incentive schemes. ${ }^{5}$ For an overview of the experimental settings considered in these studies see Table 1. Table 2 summarized their findings. Most of the studies focus on a single activity dimension which means that the exertion of sabotage activities is not modeled. Furthermore, in general the tournament design is exogenously given without allowing for the interaction of the principal and the agents. By the present study we aim to complement previous work by focusing on the behavioral investigation of the interaction between principal and agents if the principal can alter the magnitude of the winner prize. The studies mostly related to the current one are HARBring and IRLENBUSCH (2003c), HARBring and IRLENBUSCH (2003e) and FALK and FeHR (in preparation). In HARBRING and IRLENBUSCH (2003c) the impact of different exogenously given tournament design features - the proportion of winner prizes as well as their magnitude - on the behavior of agents is analyzed. Agents may also exert destructive activities. This study, however, focuses on the influence of an exogenously given tournament design where the wage sum is fixed in each treatment and the principal cannot actively choose between different design parameters. Thus, there is no bilateral interaction between the principal and the agents. In contrast, in HARBRING and IRLENBUSCH (2003e) the principal can either vary the prize spread and/or the wage sum. The results, however, are not compared with analogous passive principal treatments and therefore the interaction effects between principals and agents cannot be isolated ceteris paribus. The latter is also true for the study from FALK and FEHR (in preparation). Concurrently and independently from us they work on an experimental study to investigate the behavior of a principal and agents in a setting with sabotage. Their research focus, however, lies in the variation of the wage spread and consequently the principal does not choose between different wage sums. ${ }^{6}$

\footnotetext{
${ }^{5}$ For theoretic studies on a variety of topics concerning tournaments see e.g. LAZEAR and ROSEN (1981), GREEN and STOKEY (1983), NALEBUFF and STIGLITZ (1983) and CLARK and RIIS (1998). For an alternative modeling of relative competition in contests see the experimental studies of MÜLLER and SCHOTTER (2003) and HARBRING, IRLENBUSCH, KRÄKEL, and SELTEN (2004).

6 Note that FALK and FEHR (in preparation) model sabotage as a binary decision. If it is exerted it destroys the complete output of the other agent. Quite interestingly, they also conduct a random matching treatment which to our knowledge is the first study with such a scheme. They find that effort is higher in the random matching treatment than in the fixed matching treatment, especially for high prize spreads.
} 
study

main results

BULL, SCHOTTER,
WEIGELT (1987)
WEIGELT, DUKERICH,
SCHOTTER (1989)
SCHOTTER,
WEIGELT (1992)
NALBANTIAN,
SCHOTTER (1997)
HARBRING,
IRLENBUSCH (2001)
VAN DIJK, SONNEMANS,
VAN WINDEN (2001)

GNEEZY, NiEDERLE, RUSTICHINI (2003)

HARBRING (2003)

HARBRING, IRLENBUSCH (2003a)

HARBRING, IRLENBUSCH (2003b)

HARBRING, IRLENBUSCH (2003c)

HARBRING, IRLENBUSCH (2003d)

HARBRING, IRLENBUSCH (2003e)

ORRISON, SCHOTTER, WEIGELT (2004)

HARBRING, RUCHALA (2004)

FALK, FEHR (in preparation) on average equilibrium predictions are confirmed in symmetric tournaments; mean average effort levels exerted by disadvantaged agents are above equilibrium effort; higher effort variance in tournaments compared to piece rates

on average equilibrium predictions are confirmed in symmetric tournaments; in asymmetric tournaments average observed effort levels are higher than equilibrium prediction

high variance across subject behavior; slight oversupply of effort compared to equilibrium; compensating for discrimination increases effort because drop-outs are avoided

competitive team mechanism dominates various other team incentive schemes with regard to higher mean effort levels and smaller across-group variances of effort

effort higher in team compensation than in tournaments because collusion in the latter; collusion among agents is reduced if the principal can choose between both schemes; variability of effort higher in tournament compensation than in team

higher effort in tournaments than in team and piece-rate schemes, but also highest variability of effort in tournaments; agents with low ability work hard and thereby drive up effort of other agents

no significant gender differences in performance between single sex tournaments; men perform higher than women in mixed groups; performance of women is higher in single sex tournaments than in piece rate treatments but does not differ in mixed sex tournaments and piece rate treatments; performance of men is higher in mixed and single sex tournaments than in piece rate treatment

communication between agents enhances their cooperation in tournament and team incentive schemes such that collusive efforts are exerted in tournaments

average effort increases with the proportion of winner prizes, mainly because the number of non-participants decreases; variability of effort over all rounds decreases with the number of winner prizes; agents in small tournaments are prone to collusion

principal chooses the highest fraction of winner prices to reward agents while the minimal amount of winner prizes is intended to punish agents; Productive and destructive activities increase with the number of winner prizes but the increase of the productive effort overcompensates the increase in sabotage

inexperienced participants exert higher productive effort if the fraction of winner prizes is balanced; the sabotage problem is exacerbated by an increase in the prize difference;

ceteris paribus tournament size has virtually no effect on behavior; a balanced fraction of winner prizes and loser prizes enhances productive activity

high wage sums are surprisingly often implemented; principals quite often rely on fixed wages; higher output is generated when the wage sum is high; effort and sabotage increases with the wage spread but output does not; with communication high fixed wages are chosen, which reduces sabotage and thus increases efficiency

ceteris paribus tournament size has no effect on behavior; tournaments with a relatively high proportion of high prizes elicit low effort

effort increases with the wage spread; only when the wage spread is high strong agents win the tournament more often than weak agents;

frequency of sabotage increases with wage spread; principal chooses low wage spreads if sabotage is possible otherwise high wage spreads are selected; communication between agents leads to more pronounced collusive behavior 
The rest of the paper proceeds as follows. In the next section, we introduce and analyze a simple tournament model with two activity dimensions. Section III deals with the experimental setting based on the model described. In section IV we present the experimental results. We begin with the treatments in which tournament prizes are exogenously given and which serve as our baseline treatments. The analysis of our interaction treatment follows, where in each round a principal endogenously commits himself to a certain magnitude of the winner prizes. Section V concludes the paper.

\section{A simple model of tournaments with two activity dimensions}

In this section, we introduce a simple model of rank-order tournaments, in which agents can choose between activities from two dimensions: productive effort and sabotage. We consider a situation in which it is relatively easy to hide sabotage and we abstract from the possibility of control activities and detection. The following model characterizes the strategic situation faced by the participants in our experiment. We consider a game of $n+1$ players i.e. $n$ agents and one principal. The agents take part in a tournament in which they compete for $\lambda n$ winner prizes $(0<\lambda<1)$, i.e. agents with the $(1-\lambda) n$th lowest output or less receive loser prizes. We denote the winner prize by $M$, the loser prize by $m(M>m)$ and the prize difference $(M-m)$ by $\Delta$. A strategy of agent $i$ is a pair $\left(e_{i}, s_{i}\right)$ where $e_{i} \in[0, \ldots, \bar{e}]$ denotes an effort level and $s_{i} \in[0, \ldots, \bar{s}]$ is a sabotage activity. The latter negatively influences the output of all other agents, i.e. the output $y_{i}$ of agent $i$ is determined by the following production function

$$
y_{i}=e_{i}+\varepsilon_{i}-\sum_{i \neq j} s_{i} .
$$

Observed production is assumed to be distorted in the sense that the effectiveness of effort and sabotage may be influenced by luck. The noise is represented by a random variable $\varepsilon_{i}$, which is uniformly distributed over the interval $[-\bar{\varepsilon},+\bar{\varepsilon}]$ and assumed to be i.i.d. for all agents. Every agent who exerts effort or performs a sabotage activity has to bear costs, which are described by the two convex functions $C_{e}\left(e_{i}\right)$ and $C_{s}\left(s_{i}\right){ }^{7}$ All agents simultaneously submit their effort and sabotage decisions. The expected payoff for agent $i$ is given by

$$
E \Pi_{i}\left(e_{i}, e_{-i}, s_{i}, s_{-i}\right)=F\left(e_{i}, e_{-i}, s_{i}, s_{-i}\right) M+\left[1-F\left(e_{i}, e_{-i}, s_{i}, s_{-i}\right)\right] m-C_{e}\left(e_{i}\right)-C_{s}\left(s_{i}\right)
$$

\footnotetext{
7 Note, that we implement the same cost functions for all agents. We do not analyse the behaviour of heterogeneous "personalities" like "doves" and "hawks" as in LAZEAR (1989) who models agents with different marginal costs of sabotage.
} 
with $F\left(e_{i}, e_{-i}, s_{i}, s_{-i}\right)$ denoting the probability for agent $i$ to receive a winner prize if all other agents choose effort levels $e_{-i}=\left(e_{1}, e_{2}, \ldots, e_{i-1}, e_{i+1}, \ldots, e_{n}\right)$ and sabotage activities $s_{-i}=\left(s_{1}, s_{2}, \ldots, s_{i-1}, s_{i+1}, \ldots, s_{n}\right)$.

As a benchmark let us have a look at the equilibrium behavior. For simplicity, we concentrate on cost functions of the type $C_{e}\left(e_{i}\right)=e_{i}{ }^{2} / c_{e}$ and $C_{s}\left(s_{i}\right)=s_{i}{ }^{2} / c_{s}$. We assume that all agents are risk neutral and purely money maximizing ${ }^{8}$. The expected payoff of the agents can be written as

$$
E \Pi_{i}\left(e_{i}, e_{-i}, s_{i}, s_{-i}\right)=m+F\left(e_{i}, e_{-i}, s_{i}, s_{-i}\right) \Delta-e_{i}^{2} / c_{e}-s_{i}{ }^{2} / c_{s} .
$$

If there exists an interior equilibrium, the first order conditions have to hold:

$$
\frac{\partial F\left(e_{i}, e_{-i}, s_{i}, s_{-i}\right)}{\partial e_{i}} \Delta=\frac{2 e_{i}}{c_{e}} \text { and } \frac{\partial F\left(e_{i}, e_{-i}, s_{i}, s_{-i}\right)}{\partial s_{i}} \Delta=\frac{2 s_{i}}{c_{s}} \text {. }
$$

Given our assumptions on the distribution of the random components in the production function one can show that in a symmetric equilibrium the marginal probabilities of winning are constant and depend only on the size of the interval from which the random components are drawn (see Appendix) ${ }^{9}$, i.e. one can show that

$$
\frac{\partial F\left(e_{i}, e_{-i}, s_{i}, s_{-i}\right)}{\partial e_{i}}=\frac{\partial F\left(e_{i}, e_{-i}, s_{i}, s_{-i}\right)}{\partial s_{i}}=\frac{1}{2 \bar{\varepsilon}} .
$$

Thus, our first order conditions reduce to

$$
\frac{1}{2 \bar{\varepsilon}} \Delta=\frac{2 e_{i}}{c_{e}} \wedge \frac{1}{2 \bar{\varepsilon}} \Delta=\frac{2 s_{i}}{c_{s}}
$$

from which we obtain the effort level and the sabotage activity played in symmetric equilibrium

$$
e^{*}=\frac{\Delta c_{e}}{4 \bar{\varepsilon}} \quad \text { and } \quad s^{*}=\frac{\Delta c_{s}}{4 \bar{\varepsilon}}
$$

To ensure that an interior solution exists and that agents have no incentive to deviate to activities of zero the following condition is assumed be satisfied: $\lambda \Delta \geq C_{e}\left(e^{*}\right)+C_{s}\left(s^{*}\right)$, i.e. the expected gain of an agent must not be lower than his cost. Thus, the parameters have to be chosen such that this condition is fulfilled. Moreover, the highest possible eligible effort level

\footnotetext{
${ }^{8}$ For the analysis of tournaments with inequity averse agents see DEMOUGIN and FLUET (2003) and GRUND and SLIWKA (2003). They apply a FEHR and SCHMIDT (1999) type of preference and find that inequity averse subjects exert higher activities compared to the standard prediction with completely selfish individuals if prizes are exogenously given.

9 Proofs for the cases $\lambda=1 / n$ and $\lambda=(n-1) / n$ are given by KrÄKEL (2000). ORRISON, SCHOTTER, and WEIGELT (2004) sketch a similar argumentation as we do.
} 
must exceed the equilibrium effort level, i.e. $e^{*}<\bar{e}$. An analogous statement holds for the sabotage activity $\left(s^{*}<\bar{s}\right)$.

It is worth noting, that within our framework the equilibrium activity levels do neither depend on the tournament size $n$ nor do they change with the fraction $\lambda$ of winner prizes. Essentially, this is due to the fact that the marginal probability of winning is constant under the assumption of $\varepsilon$ being uniformly distributed. Note, however, that an increase in the prize difference leads to higher effort as well as higher sabotage activities in equilibrium.

The principal in our setting is remunerated in proportion to the output generated by the agents. Thus, his expected payoff increases with the total productive effort exerted by the agents and decreases with the total average sabotage activity:

$$
E \Pi_{P}(e, s)=\tau\left[E\left(\sum_{i} y_{i}\right)\right]-\theta W=\tau\left[\sum_{i} e_{i}-\sum_{i} \sum_{j \neq i} s_{j}\right]-\theta W
$$

where $\tau$ indicates the value of one unit of output for the principal and the principal bears a fraction $\theta$ of the total wage costs $W=n[\lambda M+(1-\lambda) m]$.

Our main research question is whether, and if so, how the principal's choice of the tournament design affects the behavior of the agents. In order to keep our setting reasonably simple, in this study we concentrate on a situation, in which the principal is given one of the major design options for altering the pay structure, i.e. the choice of the winner prize. We assume everything else to remain constant. ${ }^{10}$ On the one hand, in equilibrium a higher winner prize induces the agents to exert more effort and more sabotage as one can see from the equilibrium predictions derived above. On the other hand a higher winner prize increases the total wage costs for the principal. In equilibrium the principal receives the following expected payoff which varies with the winner prize $M$ :

$$
E \Pi_{P}\left(e^{*}, s^{*}\right)=\frac{\tau(M-m) n}{4 \bar{\varepsilon}}\left[c_{e}-(n-1) c_{s}\right]-\theta[\lambda n M+(1-\lambda) n m]
$$

Thus, the payoff is linearly increasing in $M$ by the factor $\frac{\tau n}{4 \bar{\varepsilon}}\left[c_{e}-(n-1) c_{s}\right]-\theta \lambda n$. One can see that if the condition $\left[c_{e}-(n-1) c_{s}\right]>0$ holds, the principal's choice of a higher winner prize, i.e. a higher wage spread, results ceteris paribus in a positive agents' output change. Another implication is that the principal's expected payoff in equilibrium does virtually not

\footnotetext{
${ }^{10}$ One might think of various other design options like the number of agents participating in a tournament or the proportion of winner prizes.
} 
change if the expressions $\frac{\tau n}{4 \bar{\varepsilon}}\left[c_{e}-(n-1) c_{s}\right]$ and $\theta \lambda n$ are of the same magnitude. This condition will be used when we choose the parameters in the experimental design.

\section{Experimental Design and Procedure}

The experimental design reflects our aim to investigate the influence of a principal's commitment to a specific tournament design. In our interaction treatment we allow the principal to vary the winner prize. Afterwards the agents are informed about the principal's choice and they have to decide about the effort and sabotage activity they want to exert. As a benchmark to our interaction treatment we analyze five baseline treatments, in which the tournament prizes are exogenously given, i.e. the principal is passive and has nothing to decide.

Table 3: Parameters and design of the treatments

\begin{tabular}{|c|c|c|c|c|c|c|}
\hline & \multicolumn{6}{|c|}{ treatments } \\
\hline & \multicolumn{5}{|c|}{ baseline treatments } & interaction treatment \\
\hline winner prize $M$ & 200 & 225 & 250 & 275 & 300 & $\begin{array}{l}\text { set by principal with } \\
M \in\{200 ; 225 ; \ldots 300\}\end{array}$ \\
\hline loser prize $m$ & 100 & 100 & 100 & 100 & 100 & 100 \\
\hline prize differential $\Delta$ & 100 & 125 & 150 & 175 & 200 & $M-100$ \\
\hline productive effort $e^{*}$ & 32 & 40 & 48 & 56 & 64 & dependent on $\Delta$ \\
\hline sabotage activity $s^{*}$ & 8 & 10 & 12 & 14 & 16 & dependent on $\Delta$ \\
\hline cost of effort $C_{e}\left(e^{*}\right)$ & 13.33 & 20.83 & 30.00 & 40.83 & 53.33 & dependent on $\Delta$ \\
\hline cost of sabotage $C_{s}\left(s^{*}\right)$ & 3.33 & 5.21 & 7.50 & 10.21 & 13.33 & dependent on $\Delta$ \\
\hline output & 32 & 40 & 48 & 56 & 64 & dependent on $\Delta$ \\
\hline \multicolumn{7}{|l|}{ design } \\
\hline \# principals & 8 & 8 & 8 & 8 & 8 & 8 \\
\hline \# agents & 32 & 32 & 32 & 32 & 32 & 32 \\
\hline \# observations & 8 & 8 & 8 & 8 & 8 & 8 \\
\hline \# rounds & 20 & 20 & 20 & 20 & 20 & 40 \\
\hline
\end{tabular}

We consider tournaments with $n=4$ agents and a fraction of winner prizes of $\lambda=1 / 2$. Additionally, for each tournament one subject is assigned the role of the principal. Table 3 shows the parameter specification of our treatments. In all treatments the loser prize $m$ is set to 100 "talers", which is the fictitious currency we use in the experiment. The winner prize varies along treatments. 
All agents $i$ have to choose their effort levels $e$ and their sabotage activities $s$ simultaneously from the following sets of integers: $e \in\{0, \ldots, 100\}$ and $s \in\{0, \ldots, 50\}$. The random variable $\varepsilon_{i}$ as one part of the output of agent $i$ is uniformly distributed (i.i.d. for all agents) over the integer interval $[-60,+60]$. We use the parameters $c_{e}=76.8$ and $c_{s}=19.2$ which lead to the cost functions $C_{e}\left(e_{i}\right)=e_{i}^{2} / 76.8$ and $C_{s}\left(s_{i}\right)=s_{i}{ }^{2} / 19.2$. The cost functions reflect the assumption that the sabotage activity is more expensive than productive effort because, in general, it is difficult to hide destructive activities. Table 3 contains the corresponding equilibrium effort and sabotage levels for all treatments. The surplus share $\tau$ for the principal is set to .5 .

In our interaction treatment the principal has to select the winner prize in each round from the set of winner prizes, which are implemented in our five baseline treatments. The sequence of the game is shown in Figure 1.

\begin{tabular}{l|l|l|l|} 
lst stage: decision of principal & \multicolumn{2}{c}{ 2nd stage: decisions of agents } \\
\hline & \begin{tabular}{|l|l|l} 
Agents are informed \\
about wage contract \\
$M \in\{200 ; 225 ; 250 ; 275 ; 300\}$
\end{tabular} & $\begin{array}{l}\text { Agents choose } \\
\text { productive effort } e_{i} \text { and } \\
\text { sabotage activity } s_{i}\end{array}$ \\
\hline
\end{tabular}

Figure 1: Sequence of the game in the interaction treatment

The principal's payoff is calculated as described above with $\theta=0.1$ as the fraction of the wage costs he has to bear. For deriving the subgame perfect equilibrium it is important to note that the principal determines the prize differential as well as the total sum of wages by selecting the winner prize. According to the equilibrium behavior of agents described above and our parameter specification a higher prize differential is accompanied by a higher output. However, total wage costs are also increased by strengthening tournament incentives. We have chosen the parameter values such that the principal is almost indifferent between the winner prizes that can be chosen, if he assumes that the agents show equilibrium behavior in the following subgame. Thereby, we tried not to make the choices of one of the winner prizes less likely by the experimental design. ${ }^{11}$

The experiment was conducted in the Laboratories for Experimental Research at the Universities of Bonn and Erfurt. All sessions were computerized and the software was developed by using RatImage (ABBINK and SADRIEH, 1995). In total 240 students of different disciplines were involved in the experiment - 192 take part as agents and 48 as principals.

\footnotetext{
11 In fact the principal has a slight preference (of one taler) for the lowest winner prize. However, if all agents choose equilibrium strategies agents' payoff is maximal with a winner prize of $M=250$.
} 
Every candidate was only allowed to participate in one session. We collected eight independent observations for each treatment. After the instructions participants were randomly and anonymously matched to groups of four agents. ${ }^{12}$ Additionally, one participant was randomly and anonymously assigned to each group as their principal. The experimental game was repeated for 20 rounds in the baseline treatments and for 40 rounds in the interaction treatment. The matching of the agents and the principal was fixed for the whole experiment. This models a situation in which the same people repeatedly find themselves in a tournament interaction as it is often the case in employment relationships. In all treatments the principal was informed about each agent's output after each round. Agents were shown the principal's payoff after each round.

In the baseline treatments all principals were seated in a room separated from the cubicles of the agents. Remember, that the principal had no decision to take in the baseline treatments. However, it was their duty to calculate their own earnings in each round based on the output of agents that were traced on a computer screen. In the interaction treatment the principals as well as the agents were seated in cubicles.

The sessions lasted for about 1.5 to 2.5 hours. During the experiment the payoffs were given in talers and in the end they were converted into Euro by a previously known exchange rate of 100 talers per 0.51 Euro. All subjects were paid anonymously.

\section{Results}

In this section, we provide experimental evidence beginning our analysis with the baseline treatments. In subsection IV.2 we compare the findings from the baseline treatments with those from the interaction treatment, where a principal may endogenously select the winner prize.

\section{IV.1 Baseline treatments with exogenous winner prize}

Following the theoretic predictions effort and sabotage should increase with the prize spread. In fact, we can strongly confirm the standard prediction of tournament theory regarding this aspect.

\footnotetext{
12 A translation of the instruction sheet can be found in the appendix. Original instructions in German are available from the authors upon request.
} 
RESULT 1: Effort as well as sabotage increases with the winner prize.

Table 4 gives an overview of the data concerning the average amount of effort and sabotage exerted in the baseline treatments with an exogenous winner prize. The data shows that effort increases significantly with a higher winner prize. The same is true for sabotage. While in Table 4 the ranking of results is confirmed by a single statistical test, Table 5 additionally supplies the results of pairwise testing also indicating that both activities are increasing with the winner prize.

Table 4: Overview of results in baseline treatments with exogenous winner prizes

\begin{tabular}{|c|c|c|c|c|c|c|}
\hline & $M=200$ & $M=225$ & $M=250$ & $M=275$ & $M=300$ & $\begin{array}{c}\text { Jonckheere- } \\
\text { Terpstra } \\
\text { test }^{13} \\
\end{array}$ \\
\hline average effort & $43.99++$ & $47.44+$ & 52.65 & 60.16 & 56.16 & $\alpha=.012$ \\
\hline effort in equilibrium & 32 & 40 & 48 & 56 & 64 & \\
\hline $\begin{array}{l}\text { average cost of effort } \\
\text { cost of effort in equilibrium }\end{array}$ & $\begin{array}{c}34.71++ \\
13.33\end{array}$ & $\begin{array}{c}39.95++ \\
20.83\end{array}$ & $\begin{array}{c}46.74+ \\
30\end{array}$ & $\begin{array}{c}58.60+ \\
40.83\end{array}$ & $\begin{array}{l}48.08 \\
53.33\end{array}$ & $\alpha=.005$ \\
\hline $\begin{array}{c}\text { average sabotage } \\
\text { sabotage in equilibrium }\end{array}$ & $\begin{array}{c}11.60++ \\
8\end{array}$ & $\begin{array}{c}17.00+ \\
10\end{array}$ & $\begin{array}{c}16.17+ \\
12\end{array}$ & $\begin{array}{c}22.26+ \\
14\end{array}$ & $\begin{array}{c}21.54+ \\
16\end{array}$ & $\alpha=.003$ \\
\hline $\begin{array}{c}\text { average cost of sabotage } \\
\text { cost of sabotage in } \\
\text { equilibrium }\end{array}$ & $\begin{array}{c}12.30++ \\
3.33\end{array}$ & $\begin{array}{l}25.11++ \\
\quad 5.21\end{array}$ & $\begin{array}{l}21.45++ \\
\quad 7.5\end{array}$ & $\begin{array}{c}36.38++ \\
10.21\end{array}$ & $\begin{array}{c}31.90++ \\
13.33\end{array}$ & $\alpha=.000$ \\
\hline average output & 36.73 & $-8.84 *$ & 16.56 & -26.49 & $-33.85 *$ & $\alpha=.012$ \\
\hline output in equilibrium & 32 & 40 & 48 & 56 & 64 & \\
\hline $\begin{array}{l}\text { ratio of marginal costs of } \\
\text { sabotage and effort }\end{array}$ & 1.06 & $1.43+$ & 1.26 & 1.52 & $1.55+$ & $\alpha=.012$ \\
\hline
\end{tabular}

By using the Binomial Test (one-tailed) we state the level of significance at which the null hypothesis can be rejected in favor of the alternative hypothesis that the average values are more often above (below) the equilibrium level than below (above):
$+\quad$ significantly above the equilibrium level:
$.05 \leq \alpha \leq .1$
++ highly significantly above the equilibrium level:
$.01 \leq \alpha<.05$
significantly below the equilibrium level:
$.05 \leq \alpha \leq .1$

Comparing the observed sabotage activities with the derived benchmark from above it is obvious that agents frequently tend to choose higher sabotage activities than theoretically

\footnotetext{
13 The Jonckheere-Terpstra test is a non-parametric test for ordered differences among classes. The alternative hypothesis assumes a certain ordering of the medians of $k$ statistically independent samples. All average values each of a statistically independent observation from a treatment with the same winner prize - are assigned to one class. The level of significance results from two-tailed testing.
} 
predicted. ${ }^{14}$ To investigate the extent to which both activities are intensified due to an increase of the prize spread the ratio of the marginal costs $(M C)$ of sabotage and effort is analyzed. Theory predicts that this ratio is equal to 1 as the marginal costs of productive and destructive activities should be equal. ${ }^{15}$

Table 5: Significance levels for pairwise comparisons of baseline treatments with exogenous winner prizes (Mann-Whitney U test, one-tailed)

\begin{tabular}{|c|c|c|c|c|c|c|}
\hline $\begin{array}{l}\text { Average } \\
\text { Sabotage }\end{array}$ & Average Effort & $M=200$ & $M=225$ & $M=250$ & $M=275$ & $M=300$ \\
\hline & $M=200$ & & - & 0.05 & 0.01 & 0.05 \\
\hline & $M=225$ & 0.01 & & - & 0.05 & 0.05 \\
\hline & $M=250$ & 0.05 & - & & 0.1 & - \\
\hline & $M=275$ & 0.01 & - & 0.05 & & - \\
\hline & $M=300$ & 0.001 & 0.05 & 0.01 & - & \\
\hline
\end{tabular}

Table 4 provides the average ratio of marginal costs of sabotage and effort for each treatment. On average the ratio always lies above the theoretic prediction which indicates inefficiently strong sabotage activities compared to the exertion of effort. Moreover, the ratio becomes significantly larger with the increase of the winner prize. The average output is lower the higher the prize differential. This contradicts the theoretical prediction that stronger tournament incentives should result in higher output. The additional output that is generated via an increase in productive effort is overcompensated by an even stronger increase of the sabotage activity. In total this results in a negative output produced in most treatments. Thus, we derive our next result:

RESULT 2: The sabotage activity increases with the exogenous winner prize to a greater extent than productive effort.

\footnotetext{
14 Also average effort tends to be higher than the predicted effort level in treatments with lower winner prizes. As mentioned above DEMOUGIN and Fluet (2003) and GRUND and SliWKA (2003) find that inequity averse subjects exert higher activities compared to the standard prediction with completely selfish individuals. See also KRÄKEL (2000) for a study on the effect of relative deprivation in tournaments, in which agents are modeled similarly.

15 Note, that the comparison of the marginal cost ratios also reflects the absolute amount of sabotage exerted per unit of effort: $\left(\partial C_{s}\left(s_{i}\right) / \partial s_{i}\right) /\left(\partial C_{e}\left(e_{i}\right) / \partial e_{i}\right)=\left(2 s_{i} / c_{s}\right) /\left(2 e_{i} / c_{e}\right)=4 s_{i} / e_{i}$ as the ratio of the cost parameters is $1 / 4$.
} 
Qualitatively, agents respond to tournament incentives as predicted by standard tournament theory: Both activities - productive and destructive effort - are increasing with the winner prize respectively the prize differential. However, sabotage is intensified to a greater extent than productive effort.

\section{IV.2 Interaction treatment with endogenous winner prize}

In the interaction treatment, we allow a principal to endogenously and repeatedly commit himself to one of the winner prizes analyzed in the baseline treatments. As mentioned above we know from many experimental studies that individuals might be motivated by reciprocal fairness (see e.g. FeHR, GÄCHTER and KirChSTEIGER 1997, FALK, FeHR and FischBACHer 2000). By comparing the results of the interaction treatment to the baseline treatments we are able to identify the influence of the interaction between the agents and the principal.

One might conjecture that agents have a preference for a high total sum of wages. ${ }^{16}$ Following this assumption, agents should perceive the principal's commitment to a high winner prize as a friendly action. Being promised a high winner prize agents could react positively reciprocally and augment the principal's payoff by increasing their productive activities and simultaneously reducing their sabotage activities. Furthermore, one might conjecture that agents retaliate for a low winner prize by high sabotage activities and low effort in order to reduce the principal's payoff. Thus, reciprocally motivated agents should increase their productive effort with the winner prize and decrease their sabotage activity.

But, according to the theoretic prediction from standard tournament theory agents increase both activities if the prize differential is raised. This effect of an intensified competition by an enlarged wage dispersion is partly opposed to the behavioral conjecture regarding the reciprocal behavior which is assumed to evolve because of the variation of the total wage sum: A large winner prize should induce high productive efforts for reasons of reciprocal behavior and a stronger competition due to an increase in the prize differential. The behavior regarding the sabotage activity, however, helps to discriminate between both motives of agents. Sabotage is assumed to increase with wage dispersion if the competition for the winner prize is the agents' primary motive, and sabotage is supposed to decrease if agents aim to behave reciprocally towards the principal. Thus, our experimental set-up allows us to

\footnotetext{
${ }^{16}$ If one assumes that agents behave according to the derived symmetric equilibrium, their expected payoff is highest with a winner prize of $M=250$. But it is also reasonable to argue that agents tend to prefer the largest possible winner prizes so that the total wage sum provided is maximal. This argument is supported by the fact that the actual payoff of agents is significantly higher in the baseline treatment with $M=300$ than in all other treatments, in which prizes are exogenously given.
} 
identify whether one of these two motives dominates the other: (i) competition between the agents or (ii) reciprocal fairness towards the principal. ${ }^{17}$

Table 6 provides the key results of our experimental analysis. First of all, one can state that the principal obviously has no clear preference for one of the winner prizes. Furthermore, the average effort increases with the winner prize. ${ }^{18}$ Again, Table 6 confirms the ranking of results by a single statistical test. Additionally, Table 7 supplies the results of pairwise testing and also shows that effort is increasing with the winner prize. It appears as if sabotage slightly increases with an enlarged winner prize, but this cannot be confirmed at a conventional significance level. ${ }^{19}$ However, the average cost of sabotage borne by the agents is clearly increasing with the prize differential. Additionally, the average output seems to be stable for all winner prizes. ${ }^{20}$ The average ratios of marginal costs of sabotage and effort seem to stay constant (on average they are even decreasing, however, the trend is not significant). This is in contrast to the observation in the baseline treatments with exogenous prizes where the ratio is significantly increasing with the winner prize which is illustrated by Figure 2 . The main reason seems to be that in the interaction treatment sabotage is quite high when the announced winner prize is low.

\footnotetext{
${ }^{17}$ FeHR and FALK (1999) find that in an experimental double auction labour market the presence of reciprocal actors may substantially compromise the impact of competition on market outcomes.

18 By calculating the Kendall coefficient of concordance the degree of association among sets of rankings is determined, i.e. the amount of effort exerted with each prize differential is ranked, and the agreement of the rankings per statistically independent observation is identified. According to Kendall the best estimate of the true ranking is provided, when the Kendall coefficient is significant, by the average rank sums obtained from the rankings in each independent observation (SIEGEL and CASTELLAN 1988). The latter is true for the effort and the cost of effort. Note that we could not use the Jonckheere-Terpstra test here because the values for different winner prizes are not statistically independent.

${ }^{19}$ Interestingly, the average sabotage activity for the highest winner prize lies not significantly more often above the equilibrium level than below.

${ }^{20}$ Note that the average output is negative for each of the winner prizes.
} 
Table 6: Overview of results in the interaction treatment with variable prize spreads

\begin{tabular}{|c|c|c|c|c|c|c|}
\hline & & The $p$ & rincipal ch & looses: & & \\
\hline & $M=200$ & $M=225$ & $M=250$ & $M=275$ & $M=300$ & $\begin{array}{c}\text { of } \\
\text { concordance } \\
\text { (asymptotic) }\end{array}$ \\
\hline frequency of prize spread & $20.6 \%$ & $16.3 \%$ & $24.4 \%$ & $17.8 \%$ & $20.9 \%$ & \\
\hline average effort & $44.17+$ & 46.53 & 50.07 & 54.17 & $55.15 *$ & $\alpha=.003$ \\
\hline effort in equilibrium of subgame & 32 & 40 & 48 & 56 & 64 & \\
\hline average cost of effort & $35.45++$ & $38.40+$ & $42.43+$ & $47.86+$ & 51.12 & $\alpha=.003$ \\
\hline $\begin{array}{c}\text { cost of effort in equilbrium of } \\
\text { subgame }\end{array}$ & 13.33 & 20.83 & 30 & 40.83 & 53.33 & \\
\hline average sabotage & $18.21++$ & $18.39++$ & $19.76+$ & $21.13+$ & 21.69 & $\alpha=.105$ \\
\hline sabotage in equilibrium of subgame & 8 & 10 & 12 & 14 & 16 & \\
\hline average cost of sabotage & $26.10++$ & $27.85++$ & $31.07++$ & $34.56++$ & $36.16+$ & $\alpha=.026$ \\
\hline $\begin{array}{c}\text { cost of sabotage in equilbrium of } \\
\text { subgame }\end{array}$ & 3.33 & 5.21 & 7.5 & 10.21 & 13.33 & \\
\hline average output & $-41.81 *$ & $-34.55 *$ & -36.82 & $-36.83 *$ & $-39.62 * *$ & $\alpha=.422$ \\
\hline output in equilibrium of subgame & 32 & 40 & 48 & 56 & 64 & \\
\hline $\begin{array}{l}\text { ratio of marginal costs of sabotage } \\
\text { and effort }\end{array}$ & $1.68++$ & $1.61+$ & $1.60+$ & $1.57+$ & $1.55++$ & $\alpha=.222$ \\
\hline
\end{tabular}

By using the Binomial Test (one-tailed) the level of significance can be stated at which the null hypothesis can be rejected in favor of the alternative hypothesis that the average values are more often above (below) the equilibrium level than below (above):

$+\quad$ significantly above the equilibrium level: $\quad .05 \leq \alpha \leq .1$

$++\quad$ highly significantly above the equilibrium level: $\quad .01 \leq \alpha<.05$

* $\quad$ significantly below the equilibrium level: $\quad .05 \leq \alpha \leq .1$

* * highly significantly above the equilibrium level: $\quad .01 \leq \alpha<.05$

- Insert Figure 2 about here - 
Table 7: Significance levels for pairwise comparisons of interaction treatments with endogenous winner prizes (Wilcoxon-Signed Rank test, one-tailed)

\begin{tabular}{|c|c|c|c|c|c|c|}
\hline \multirow[b]{2}{*}{$\begin{array}{l}\text { Average } \\
\text { Sabotage }\end{array}$} & Average Effort & \multirow[b]{2}{*}{$M=200$} & \multirow[b]{2}{*}{$M=225$} & \multirow[b]{2}{*}{$M=250$} & \multirow[b]{2}{*}{$M=275$} & \multirow[b]{2}{*}{$M=300$} \\
\hline & & & & & & \\
\hline & $M=200$ & & 0.025 & 0.05 & 0.01 & 0.005 \\
\hline & $M=225$ & - & & 0.1 & 0.05 & 0.025 \\
\hline & $M=250$ & 0.1 & 0.025 & & 0.1 & 0.05 \\
\hline & $M=275$ & - & 0.05 & - & & - \\
\hline & $M=300$ & 0.1 & - & - & - & \\
\hline
\end{tabular}

This impression is confirmed if one compares the agents' behavior for each winner prize in the baseline treatments with the interaction treatment: Only one striking difference can be found regarding the sabotage and effort choices. The sabotage activity is significantly higher in the situation with the lowest winner prize if the principal endogenously commits himself to the prize differential (Mann-Whitney $\mathrm{U}$ test, $\alpha=.01$, one-tailed). ${ }^{21}$ All other pairwise comparisons for a fixed winner prize reveal no significant differences.

RESULT 3: In the situation with the lowest winner prize the sabotage activity is higher in the interaction treatment than in the baseline treatment.

\section{-- Insert Figure 3 about here --}

This result is illustrated by Figure 3. The finding that in the interaction treatment sabotage is not significantly intensified with an increase in the winner prize as it is the case in the baseline treatments, seems to be partly due to the high sabotage activity in the situation with the lowest winner prize. ${ }^{22}$

\footnotetext{
21 The ratio of marginal costs of sabotage and effort is also significantly higher if a low prize spread is chosen by the principal than in the treatment with the same prize spread that is exogenously given (Mann-Whitney U test, $\alpha=.05$, one-tailed).

22 Note that as mentioned above in our interaction model in equilibrium the principal is almost indifferent between the eligible prize levels. Therefore, it is possible that agents do not see a high level of compensation as a valuable "sacrifice". This might be a reason why we do observe no positively reciprocal reactions. We are grateful to one of the referee to suggest this explanation.
} 


\section{Conclusion}

Relative performance evaluation suffers from a severe drawback that is analyzed in this study: agents may deteriorate the other agents' performance to improve the own relative position, i.e. they can sabotage each other. Sabotage is forbidden in real-world organizations, and as a consequence data on sabotage can barely be collected. Therefore, we approach the problem by a controlled laboratory experiment. An experimental study of a simple tournament model with two activity dimensions is provided: a productive and a destructive activity (sabotage). Agents compete for attaining one of the winner prizes by exerting productive effort and sabotage whereas the latter reduces the output of all other agents in their group. Winner prizes are either exogenously given (baseline treatments) or endogenously chosen by the principal (interaction treatment).

In the baseline treatments both effort and sabotage activity increase with the winner prize. This observation qualitatively confirms standard tournament theory. However, we also find that sabotage is increased to a greater extent than productive effort if the prize differential is raised. This results in an output reduction if tournament incentives are strengthened. Thus, wage compression seems to be favorable here. A possible explanation for this finding might be that agents loose their potential considerations for the principal when tournament incentives become stronger. If winner prizes are increased an intensified sabotage activity aims at two objectives: improving the winning probability as well as lowering the principal's payoff. The latter aim may arise from inequity aversion of agents regarding the outcomes of the agents compared to the outcomes of the principal as it is modelled for example in FEHR and SCHMIDT (1999) or BoLTON and OCKENFELS (2000). Contrary to the baseline treatments there might be an additional behavioral motive in the interaction treatment where the principal can endogenously select the winner prize in each round: agents might aim to retaliate unfavorable principal's intentions. In the interaction treatment we do not find that sabotage is decreasing to a greater extent than productive effort with lowering the wage gap. Comparing the findings from the interaction treatments directly to the results from the baseline treatments allows us to conclude that there is a tendency of agents to punish unkind behavior of the principal. Positive reciprocal behavior towards the principal, however, seems not to dominate the incentive effect in the interaction tournaments. We find that the sabotage activity is much higher in the interaction treatment than in the corresponding baseline treatment if the lowest winner prize is implemented. Thus, quite distinctively agents seem to use the sabotage actively to punish the principal if he chooses very low wage levels. 
It is important to note that the average output generated is only positive, i.e. a tournament incentive scheme pays off from a principal's perspective, for low exogenously given winner prizes. If wage dispersion is high additional sabotage activities corrode additional effort. In the interaction treatment, when prizes are endogenously selected, the low wage level associated with the highest feasible degree of pay compression induces agents to choose high sabotage activities such that average output is negative for each winner prize.

Our results indicate that a severe sabotage problem may exist if performance is relatively remunerated. We do not find that the interaction between principal and agents mitigates the problem of sabotage. On the contrary, we observe that the agents use the sabotage possibility as a stick to punish the principal if the total wage sum is low. Thus, our data reveal at least two motivational driving forces for sabotage: (i) higher competition between agents; but also (ii) retaliation towards the principal if wages are perceived to be too low.

\section{References}

ABBINK, Klaus and Abdolkarim SADRIEH (1995) RatImage - Research Assistance Toolbox for Computer-Aided Human Behavior Experiments. SFB Discussion Paper B-325, University of Bonn.

ABBINK, Klaus, IRLENBUSCH, Bernd, RenNeR, Elke (2000) The Moonlighting Game - An Experimental Study on Reciprocity and Retribution. Journal of Economic Behavior and Organization 42, 265-277.

BECKER, Brian E. and Mark A. HusELID (1992) Incentive Effects of Tournament Compensation Systems. Administrative Science Quarterly 37, 336-350.

Bolton, Gary E and Axel Ockenfels (2000) ERC - A Theory of Equity, Reciprocity and Competition. American Economic Review (90), 166-193.

Boyle, Matthew (2001) Performance Reviews: Perilous Curves Ahead. Fortune, 15 May 2001.

Bull, Clive, Andrew Schotter, and Keith Weigelt (1987) Tournaments and Piece Rates: An Experimental Study. Journal of Political Economy 95, 1-33.

CHARNESS, Gary (2000) Responsibility and effort in an experimental labor market. Journal of Economic Behavior and Organization 42, 375-384.

Clark, Derek J. and Christian RIIS (1998) Contests With More than One Prize. American Economic Review 88, 276-89.

Demougin, Dominique and Claude Fluet (2003) Inequity Aversion in Tournaments, Discussion Paper, Humboldt University Berlin.

Drago, Robert W. and Gerald T. GarveY (1998) Incentives for Helping on the Job. Theory and Evidence. Journal of Labor Economics 16(1), 1-15.

DufWENBERG, Martin and Georg KIRCHSTEIGER (2000) Reciprocity and Wage Undercutting. European Economic Review 44, 1069-1078.

EhrenberG, Ronald G. and Michael L. Bognanno (1990) The Incentive Effects of Tournaments Revisited: Evidence from the European PGA Tour. Industrial and Labor Relations Review 43, 74s-88s.

ERIKSSON, Tor (1999) Executive Compensation and Tournament Theory: Empirical Tests on Danish Data. Journal of Labor Economics 17(2), 262-280.

FALK, Armin, Ernst FeHR, and Urs FischBACHER (2000) Testing Theories of Fairness - Intentions Matter. Discussion Paper, University of Zurich. 
FALK, Armin and Ernst FEHR (in progress) The Power and Limits of Tournament Incentives.

FEHR, Ernst, Simon GÄCHTER and Georg KIRCHSTEIGER (1997) Reciprocity as a Contract Enforcement Device: Experimental Evidence. Econometrica 64 (4), 833-860.

FEHR, Ernst and Armin FALK (1999) Wage rigidity in a competitive incomplete contract market. Journal of Political Economy 107, 106-34.

FeHR, Ernst and Klaus SchMIDT (1999) A Theory of Fairness, Competition, and Cooperation. Quarterly Journal of Economics 114, 817-868.

Garicano, Luis and Ignacio Palacios-Huerta (2000) An Empirical Examination of Multidimensional Effort in Tournaments. Discussion Paper, University of Chicago.

GIBBONS, Robert (1998) Incentives in Organizations. Journal of Economic Perspectives 12 (Fall 1998), 115132.

Gneezy, Uri, Muriel, Niederle Aldo Rustichini (2003) Performance in Competitive Environments: Gender Differences. Quarterly Journal of Economics, 1049-1074

Green, Jerry R. and Nancy L. Stokey (1983) A Comparison of Tournaments and Contracts. Journal of Political Economy 91, 349-64.

GRUND, Christian and Dirk SLIWKa (2002) Envy and Compassion in Tournaments, forthcoming in Journal of Economics and Management Strategy.

HARBRING, Christine (2003): The Effect of Communication in Incentive Systems - An Experimental Study. Discussion Paper, University of Bonn.

HARBRING, Christine and Bernd IRLENBUSCH (2001) Eine experimentelle Studie zur strategischen Wahl von Entlohnungsschemata. Zeitschrift für Betriebswirtschaft, Ergänzungsheft 4/2001, Theorie der Unternehmung, 175-193.

HARbring, Christine and Bernd Irlenbusch (2003a) An Experimental Study on Tournament Design. Labour Economics 10, 443-464.

HARBring, Christine and Bernd Irlenbusch (2003b) Zur Interaktion von Arbeitgeber und Arbeitnehmern in Turnieren mit Sabotage. Zeitschrift für Betriebswirtschaft, Ergänzungsheft 4/2003, Personalmanagement 2003, 19-41.

HARBring, Christine and Bernd IRLENBUSCH (2003c) Anreize zu produktiven und destruktiven Anstrengungen durch relative Entlohnung. forthcoming in Zeitschrift für betriebswirtschaftliche Forschung.

HARbring, Christine and Bernd Irlenbusch (2003d) How Many Winners are Good to Have? - On Tournaments with Sabotage. Discussion Paper, University of Bonn and University of Erfurt.

HARBring, Christine and Bernd IRLENBUSCH (2003e) Sabotage and the Endogenous Design of Tournaments. Discussion Paper, University of Bonn and University of Erfurt.

HARbring, Christine and Gabriele Ruchala (2004) Separating the Wheat from the Chaff. Discussion Paper, University of Bonn and University of Erfurt.

Harbring, Christine, Bernd Irlenbusch, Matthias KräKel and Reinhard Selten (2004) Sabotage in Asymmetric Contests - An Experimental Analysis. Discussion Paper, University of Bonn and University of Erfurt.

Knoeber, Charles R. and Walter N. Thurman (1994) Testing the Theory of Tournaments: An Empirical Analysis of Broiler Production. Journal of Labor Economics 12, 155-79.

KRÄKEL, Matthias (2000) Relative Deprivation in Rank-Order Tournaments. Labour Economics 7, 385-407.

LAZEAR, Edward P. (1989) Pay Equality and Industrial Politics. Journal of Political Economy 97, 561-80.

LAZEAR, Edward P. (1999) Personnel Economics: Past Lessons and Future Directions - Presidential Address to the Society of Labor Economists. Journal of Labor Economics 17(2), 199-236.

LAZEAR, Edward P. and Sherwin H. Rosen (1981) Rank-Order Tournaments as Optimum Labor Contracts. Journal of Political Economy 89, 841-64.

MaIN, Brian G.M., Charles A. O’ReIlly III, and James WADE (1993) Top Executive Pay: Tournament or Teamwork? Journal of Labor Economics 11(4), 606-28. 
Mood, Alexander M., Franklin A. GraybILL, Duane C. Boes (1974) Introduction the Theory of Statistics, $3^{\text {rd }}$ edition, Mc Graw-Hill.

MÜLLER, Wieland and Andrew Schotter (2003) Workaholics and Drop Outs in Optimal Organizations. Discussion Paper, Tilburg University and New York University.

MURPHY, Kevin (1991) Performance Measurement and Appraisal: Motivating Managers to Identify and Reward Performance. William Bruns (ed.): Performance Measurement, Evaluation, and Incentives. Harvard Business School 1992.

Nalbantian, Haig R. and Andrew SchOtTeR (1997) Productivity under Group Incentives: An Experimental Study. American Economic Review 87, 314-41.

Nalebuff, Barry J. and Joseph E. Stiglitz (1983) Prizes and Incentives: Towards a General Theory of Compensation and Competition. Bell Journal of Economics 14, 21-43.

OrRison, Alannah, Andrew SchotTer, and Keith Weigelt (2004) Multiperson Tournamants: An Experimental Examination, Management Science, 50, 268-279.

Prendergast, Canice (1999) The Provision of Incentives in Firms. Journal of Economic Literature 37, 7-63.

Schotter, Andrew and Keith Weigelt (1992) Asymmetric Tournaments, Equal Opportunity Laws, and Affirmative Action: Some Experimental Results, Quarterly Journal of Economics 107, S. 511-539.

Siegel, Sidney and John N. CASTELlan (1988) Nonparametric Statistics for the Behavioral Sciences, Second Edition, McGraw-Hill.

VAN DiJK, Frans, Joep SonNemans, Frans VAN Winden (2001) Incentive Systems in a Real Effort Experiment. European Economic Review 45, 187-214.

Weigelt, Keith, Janet DuKerich, and Andrew SchOtTER (1989) Reactions to Discrimination in an Incentive Pay Compensation Scheme: A Game-Theoretic Approach. Organizational Behavior and Human Decision Processes 44, 26-44. 


\section{Figures}
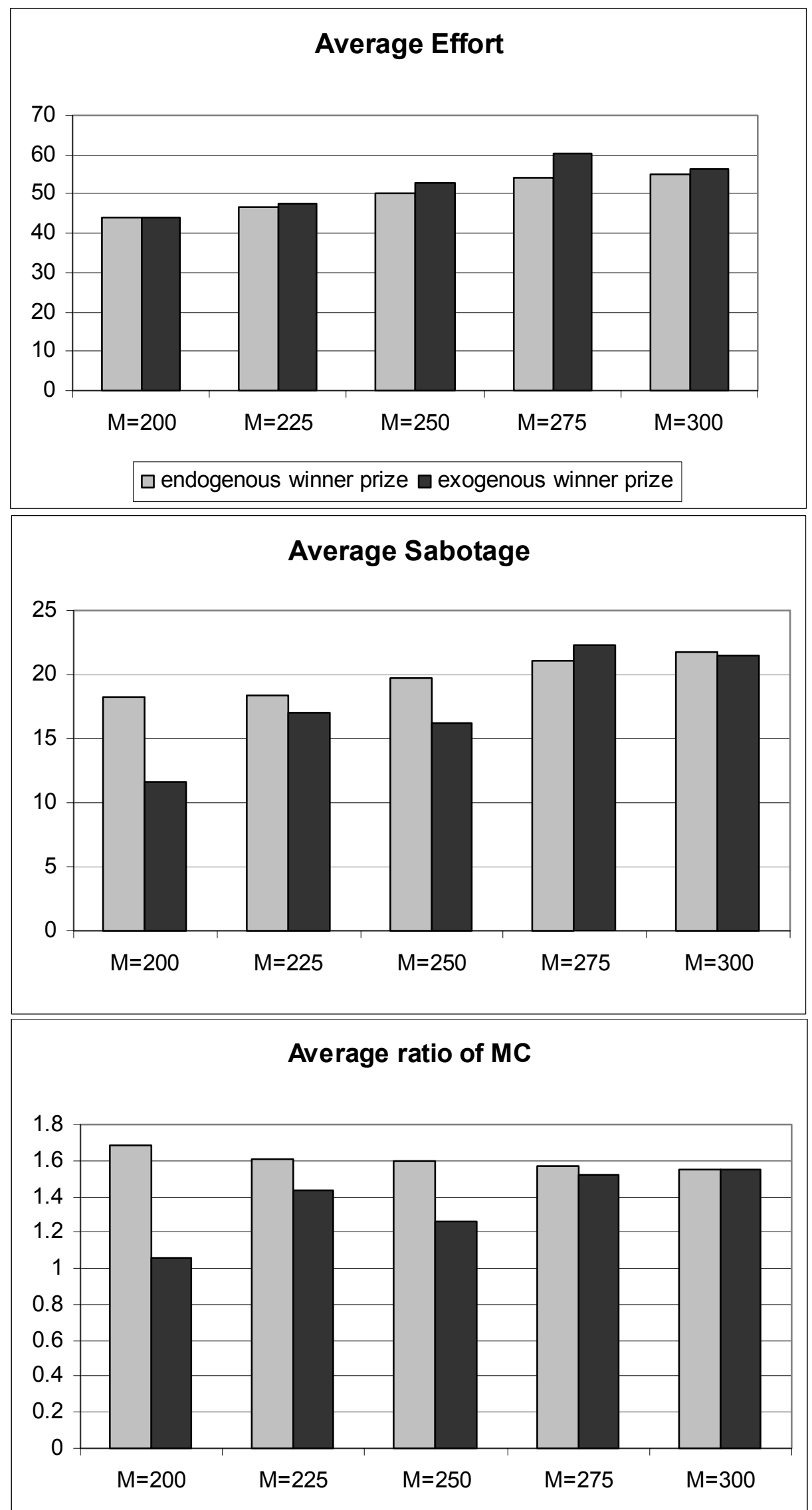

Figure 2: Average efforts, sabotage activities and ratios of marginal costs of both activities if winner prizes are exogenously given and endogenously selected 

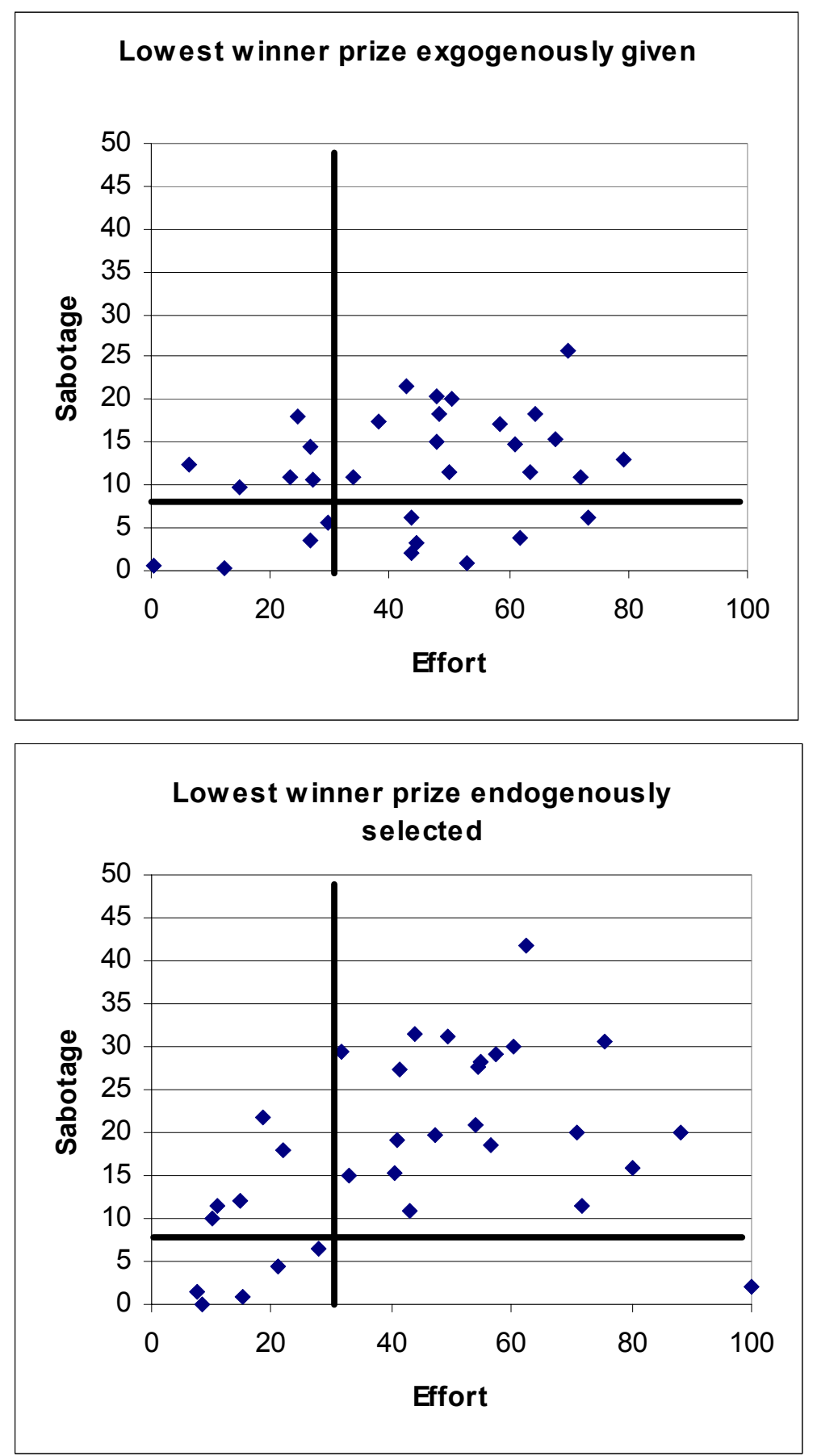

Figure 3: Average effort and sabotage exerted by each agent in the situation with the lowest winner prize (As a benchmark the equilibrium activity levels are shown.) 


\section{Appendix: Marginal Probabilities of Winning}

We show that given our assumptions in a symmetric equilibrium the marginal probabilities of winning depend only on the size of the interval from which the random component in the production function is drawn. In what follows we concentrate on the marginal probability regarding the chosen effort level. Let $\lambda n$ be the number of winner prizes $(0<\lambda<1)$, i.e., agents with the $(1-\lambda) n$th lowest output or less receive the loser prize. In a symmetric Nash equilibrium each competitor of agent $i$ will choose the same effort level $e^{*}$ and the same sabotage level $s^{*}$. Therefore, agent $i$ will receive the winner prize if her output is higher than the $(1-\lambda) n$th lowest output of the other $(n-1)$ workers, i.e., if $e_{i}+\varepsilon_{i}-(n-1) s^{*}>e^{*}-s_{i}-(n$ $-2) s^{*}+\hat{\varepsilon}$ with $\hat{\varepsilon}$ as the $(1-\lambda) n$th lowest of $(n-1)$ order statistics.

The probability for this event is $\operatorname{Pr}\left\{X<e_{i}-e^{*}-(n-1) s^{*}+s_{i}+(n-2) s^{*}\right\}=$ $F_{X}\left(e_{i}-e^{*}+s_{i}-s^{*}\right)$ with $X:=\hat{\varepsilon}-\varepsilon_{i}$ and $F_{X}(\cdot)$ as the distribution function of $X$. Agent $i$ maximizes her expected payoff $E \Pi_{i}\left(e_{i}\right)=m+\Delta F_{X}\left(e_{i}-e^{*}+s_{i}-s^{*}\right)-C_{e}\left(e_{i}\right)-C_{s}\left(s_{i}\right)$. From the assumption of a symmetric equilibrium $\left(e_{j}=e^{*}\right.$ and $s_{j}=s^{*}$ for $\left.j=1, \ldots, n\right)$ it follows that the equilibrium effort is characterized by $C_{e}{ }^{\prime}\left(e^{+}\right)=\Delta f_{X}(0)$ and $C_{s}{ }^{\prime}\left(s^{+}\right)=\Delta f_{X}(0)$ with $f_{X}(\cdot)=F^{\prime}{ }_{X}(\cdot)$ as $X^{\prime} \mathrm{s}$ density function. This leads to $e^{*}=C_{e}{ }^{,-1}\left(\Delta f_{X}(0)\right)$ as well as $s^{*}=C_{s}{ }^{,-1}\left(\Delta f_{X}(0)\right)$ with $C^{,-1}(\cdot)$ as the inverse function of the marginal cost function (note that $C_{e}{ }^{,-1}(\cdot)$ and $C_{s}{ }^{,-1}(\cdot)$ are linearly increasing). In order to obtain the equilibrium effort it remains to derive the explicit probability $f_{X}(0)$.

Let $F\left(\varepsilon_{j}\right)$ and $f\left(\varepsilon_{j}\right)$ be the distribution function and the density function of each of the $j=1, \ldots, n$ i.i.d. random components $\varepsilon_{j}$. The density function of the $(1-\lambda) n$th lowest of $(n-1)$ order statistics can be written as ${ }^{23}$

$$
\begin{aligned}
f_{(1-\lambda) n ;(n-1)}(\hat{\varepsilon}) & =\frac{(n-1) !}{[(1-\lambda) n-1] ![\lambda n-1] !} F^{n-\lambda n-1}(\hat{\varepsilon})[1-F(\hat{\varepsilon})]^{\lambda n-1} f(\hat{\varepsilon}) \\
& =\frac{(n-1) !}{[(1-\lambda) n-1] ![\lambda n-1] !}\left[\frac{\bar{\varepsilon}+\hat{\varepsilon}}{2 \bar{\varepsilon}}\right]^{n-\lambda n-1}\left[1-\frac{\bar{\varepsilon}+\hat{\varepsilon}}{2 \bar{\varepsilon}}\right]^{\lambda n-1} \frac{1}{2 \bar{\varepsilon}} \\
& =\frac{(n-1) !}{[(1-\lambda) n-1] ![\lambda n-1] !} \frac{(\bar{\varepsilon}+\hat{\varepsilon})^{n-\lambda n-1}(\bar{\varepsilon}-\hat{\varepsilon})^{\lambda n-1}}{(2 \bar{\varepsilon})^{n-1}}
\end{aligned}
$$

Now let us consider the density function $f_{X}(x)$ for the random variable $X:=\hat{\varepsilon}-\mathcal{E}_{i}$. Because $\varepsilon_{i}$ and $\hat{\varepsilon}$ are stochastically independent, we have

$$
f_{X}(x)=\int_{X=\hat{\varepsilon}-\varepsilon_{i}} f(\varepsilon) f_{(1-\lambda) n ;(n-1)}(\varepsilon+x) d \varepsilon
$$




$$
=\frac{(n-1) !}{[(1-\lambda) n-1] ![\lambda n-1] !} \int_{X=\hat{\varepsilon}-\varepsilon_{i}} \frac{(\bar{\varepsilon}+\varepsilon+x)^{n-\lambda n-1}(\bar{\varepsilon}-\varepsilon-x)^{\lambda n-1}}{(2 \bar{\varepsilon})^{n}} d \varepsilon
$$

In order to compute the density function $f_{X}(x)$ we have to fill in the limits of the integral. We know that

$-\bar{\varepsilon} \leq \varepsilon \leq \bar{\varepsilon}$

$-\bar{\varepsilon} \leq \hat{\varepsilon} \leq \bar{\varepsilon} \Leftrightarrow-\bar{\varepsilon} \leq \varepsilon+x \leq \bar{\varepsilon} \Leftrightarrow-x-\bar{\varepsilon} \leq \varepsilon \leq \bar{\varepsilon}-x$.

The random variable $X:=\hat{\varepsilon}-\varepsilon_{i}$ is distributed over the interval $[-2 \bar{\varepsilon}, 2 \bar{\varepsilon}]$, which can be divided into two subintervals: (i) $[-2 \bar{\varepsilon}, 0]$ and (ii) $[0,2 \bar{\varepsilon}]$. For $x \leq 0$ we obtain from (i) together with $(*)$ and $(* *)$ that $-x-\bar{\varepsilon} \leq \varepsilon \leq \bar{\varepsilon}$. Accordingly, for $x>0$ we obtain from (ii) together with $(*)$ and $(* *)$ that $-\bar{\varepsilon} \leq \varepsilon \leq \bar{\varepsilon}-x$.

This gives us

$$
\frac{(n-1) !}{[(1-\lambda) n-1] ![\lambda n-1] !} \int_{-x-\bar{\varepsilon}}^{\bar{\varepsilon}} \frac{(\bar{\varepsilon}+\mathcal{E}+x)^{n-\lambda n-1}(\bar{\varepsilon}-\mathcal{\varepsilon}-x)^{\lambda n-1}}{(2 \bar{\varepsilon})^{n}} d \varepsilon \quad \text { if }-2 \bar{\varepsilon} \leq x \leq 0
$$

$f_{X}(x)=$

$$
\frac{(n-1) !}{[(1-\lambda) n-1] ![\lambda n-1] !} \int_{-\bar{\varepsilon}}^{\bar{\varepsilon}-x} \frac{(\bar{\varepsilon}+\mathcal{\varepsilon}+x)^{n-\lambda n-1}(\bar{\varepsilon}-\varepsilon-x)^{\lambda n-1}}{(2 \bar{\varepsilon})^{n}} d \mathcal{\varepsilon} \quad \text { if } 0<x \leq 2 \bar{\varepsilon}
$$

In equilibrium it holds that $x=0$. It follows that

$$
f_{X}(0)=\frac{(n-1) !}{[(1-\lambda) n-1] ![\lambda n-1] !(2 \bar{\varepsilon})^{n}} \int_{-\bar{\varepsilon}}^{\bar{\varepsilon}}(\bar{\varepsilon}+\varepsilon)^{n-\lambda n-1}(\bar{\varepsilon}-\varepsilon)^{\lambda n-1} d \mathcal{\varepsilon}
$$

Repeated partial integration gives

$$
\begin{aligned}
& \int_{-\bar{\varepsilon}}^{\bar{\varepsilon}}(\bar{\varepsilon}+\varepsilon)^{n-\lambda n-1}(\bar{\varepsilon}-\varepsilon)^{\lambda n-1} d \varepsilon= \\
& =\left[\frac{1}{n-\lambda n}(\bar{\varepsilon}-\varepsilon)^{\lambda n-1}(\bar{\varepsilon}+\varepsilon)^{n-\lambda n}+\frac{(\lambda n-1)}{(n-\lambda n)(n-\lambda n+1)}(\bar{\varepsilon}-\varepsilon)^{\lambda n-2}(\bar{\varepsilon}+\varepsilon)^{n-\lambda n+1}+\ldots+\right. \\
& \left.\quad+\ldots+\frac{(\lambda n-1) !}{(n-\lambda n) \ldots(n-1)}(\bar{\varepsilon}+\mathcal{E})^{n-1}\right]_{-\bar{\varepsilon}}^{\bar{\varepsilon}} \\
& =\left[\frac{(\lambda n-1) !}{(n-\lambda n)(n-\lambda n+1) \ldots(n-1)}(2 \bar{\varepsilon})^{n-1}\right]
\end{aligned}
$$

Thus, the density reduces to

$$
f_{X}(0)=\frac{1}{2 \bar{\varepsilon}}
$$

\footnotetext{
${ }^{23}$ For the construction of order statistics see MOOD, GRAYBILL and BOES (1974).
} 


\section{Appendix: Instructions}

Baseline treatment $\Delta=100$ and interaction treatment, differences are indicated in parentheses

Original instructions were in German; they are available from the authors upon request.

\section{Rounds, Groups and Roles}

- You are participating in an experiment of [baseline: 20] [interaction: 40] rounds.

- You will be assigned to a group of 5 participants. During the experiment you will only interact with participants of your group. The group is randomly assigned and is kept constant throughout the whole experiment. It is not announced which participants are assigned to one group.

- Each participant has one of two roles: $\mathbf{1}$ participant is of type I and $\mathbf{4}$ participants are of type II.

- [baseline: The participant of type I does not have to decide anything.]

- [interaction: The participant of type I decides on the amount of payments for participants of type II in each round.]

- The task of the participants of type II is to choose a number A and a number B in each round which determine the result.

\section{Payoffs}

- Costs and payoffs are given in the fictitious currency „taler“.

Type II:

- The results of the participants of type II determine the amount of their payoffs. The two participants with the highest results receive high payments, and the two participants with the lowest results receive low payments. (In case of identical results a fair random move decides who receives a high and who a low payment.)

- [baseline: The high payment is $\mathbf{2 0 0}$ talers, and low payment is $\mathbf{1 0 0}$ talers.]

- [interaction: The high payment amounts to $200,225,250,275$ or 300 taler, depending on the decision of the participant of type I.

- The low payment amounts to $\mathbf{1 0 0}$ talers.]

- The cost for number $A$ and for number $B$, which the participant has chosen are subtracted from this payment. This results in the payoff of the round.

[baseline: Type I:

- The participant of type I receives half of the results of the participants of type II in her/his group. In addition, she/he receives 200 talers in each round.]

[interaction: Type I:

- The participant of type I receives half of the results of the participants of type II in her/his group. In addition, she/he receives 200 talers in each round.

- Moreover, $10 \%$ of the two low payments and two high payments is subtracted from his payoff in each round.

round payoff of type $I=0.5 *$ results of all participants +200 Taler

-0.1 ( $2 *$ low payment $+2 *$ high payment ) 


\section{Procedure of a round and calculation of results}

- [interaction: Each participant of type I selects a high payment of 200, 225, 250, 275 or 300 taler for the participants of type II.

- The participants of type II are informed about the decision of their type I participant.]

- Each participant of type II chooses a number $\mathbf{A}$ from the set $\{0, \ldots, 100\}$ and a number $\mathbf{B}$ from the set $\{0, \ldots, 50\}$. For both numbers a participant has to bear the costs listed in the two cost tables. The higher the numbers chosen the higher are the costs.

- For each participant of type II a random number is drawn independently from the set $\{-60, \ldots,+60\}$. Each number is drawn with the same probability.

- The result of a participant is the sum of her/his random number and the number $A$ chosen by her/him. Moreover, all numbers B are deducted which the three other participants of type II have chosen. Thus, the result of a participant of type II increases with the own number A and decreases with the numbers B of the other three participants of type II.

\section{Result $=$ own number $A$ - numbers $B$ of other participants + random number}

A participant of type II is only informed about her/his own payoff (not her/his result) and the payoff of the participant of type I. The participant of type I is informed about the results of the other four participants in each round.

At the end of the experiment the sum of all payoffs of each round is exchanged at an exchange rate of 0.51 Euro per 100 Taler. 